The meeting emphasized the importance of scientific documentation centres, particularly in developing countries. Such centres had now beon established, with the assistance of Uneseo, in India, Pakistan and the Philippines, whilo one was being set up in Thailand and another planned in Indonesia. It was suggested that it would be impossible for each centre to build up a completely comprehensive service and the Unesco South-East Asia Science Co-operation Office at Djakarta was asked to examine the possibility of elose liaison and co-ordination between the various centres. The Office was also asked to study the possibility of establishing regional scientific journals in the area. Although there was little difficulty in placing scientific papers in international journals in basic subjects like physics and chemistry, it was often hard to provide for publication of papers of specialized regional interest, for example, zoology, parasitology, botany, phytochemistry. Because of cost and limitod output of papers, it was difficult for smaller countries to establish thoir own journals to cater for this type of matorial. Regional journals in such subjects would overcome the difficulties and ensure that the work could be properly recorded and made more readily available by libraries.

The mocting also examined a number of other aspects of co-operation, for example, technical assistance, regional collaboration in research and training, the exchange of scientists, regional scientific meotings, etc. The formal outcome of the meeting was a series of recommendations to the DirectorGeneral of Unesco that the South-East Science
Co-operation Office should indertake a number of specific activities designed to strengthen the development of science in the countries of the region. The meeting also emphasized the importance of the work being carried out by tho Office, which thoroughly justified the provision of additional funds to enable a substantial expansion of its activities.

The South-East Asia region embraces countries the stage of development of which varies over an extremely wide range, and the conference-more effective perhaps because of its small size and intimacy-should make a contribution towards achieving the purpose of the recommondations of the Auger Report: the better utilization of science for improving living standards. This is a goal which is common to the countries of the region, as is evidenced by the establishment or planning of national research organizations by all the Governments concerned. The desire for constructive international co-operation, demonstrated convincingly at this moeting as well as at Bandung, should have important practical results in holping the growth and work of these organizations, particularly in the less-developed countries. It should also have as a secondary, though no less important, consequence, a political dividend in the building up of international trust and confidence. This may be small in relation to the magnitude of international tensions, but it is nevertheless an important aspect of international scientific gatherings, particularly those like that described where there is a common interest in working together for constructive ends. GUY B. GRESFORD

\title{
OBITUARIES
}

\section{Prof. A. H. Compton}

Arthur Holly Compton died on March 15 in Berkeley, California, as a result of cerebral hæmorrhage suffered two weeks earlier. He was sixty-nine.

He had retired last year as distinguished service professor of natural philosophy in Washington University (St. Touis), where he had served as chancellor from 1945 until 1953 . He was planning to be active in retirement as professor-at-large between Washington University, the University of California (Berkeley) and the College of Wooster (Ohio), and had gone to Berkeley to deliver a lecture series on "Man, Science and Society".

Compton roceived his B.Se. from the College of Wooster, where his father, Elias Compton, was professor of philosophy, and received his Ph.D. in 1916 at Princeton University. The next year he was an instructor at the University of Minnesota, and then was for two years a research ongineer for the Westinghouse Lamp Company in Pittsburgh. 'The year 1919-20 was spent at Cambridge (England) as a National Research Fellow, after which he was appointed Wayman Crow professor and head of the Department of Physies at Washington University, where he remained until 1923. During 1923-45 he scrved as professor of physies and dean of physical sciences at the University of Chicago, until he returned to Washington University as chancellor in 1945. He was president of the American Physical Society in 1934, of the American Association of Scientific Workers in 1939-40 and of the American Association for the Advancement of Science in 1942. In 1927 he shared the Nobel Prize in physics with C. T. $R$. Wilson.

His career was marked by an extraordinary range of great accomplishments in physics, in higher education, in war-time scientific research, and in efforts to improve human and international relations.

While a student at Princeton he devised a beautiful demonstration of the Earth's rotation, which ought to be known to all teachers of physics. A toroidal glass tube is filled with water, and mounted so that it can be 'flipped' through $180^{\circ}$ about a diameter as axis. Before flipping, the water is at rest relative to the tube, which is turning, relative to the fixed stars, in its own plane with the component of the Earth's rotational angular velocity normal to that plane. After flipping, the water drifts relative to the tubs, at a rate proportional to that angular velocity component. By measuring the drifts produced by three successive flips about each of three mutually perpendicular axes, one finds the Earth's angular velocity as a vector; that is, one can infer which local direction is north, what is the observer's latitude, and what is the absolute value of the length of the day.

His first major discovery was the detailed measurement and interpretation of the wave-length change occurring when X-rays are scattcred, especially by materials of low atomic number. This is now gonerally known as the Compton effect. He showed that the loosely bound electrons in the material scatter the $\mathrm{X}$-rays in accordance with the principles of conservation of momentum and energy, as if thoy consist of a stream of photons, each having momentum 
of $h v / c$, as well as energy, $h v$. The energy aspect goes back to Planck and Einstein; but the Compton effect afforded the first clear demonstration that the X-ray photons also carry quantized amounts of momentum.

The next few years were marked by the development of coincidence methods by Compton and A. W. Simon in Chicago, and independently by W. Bothe and $\mathbf{H}$. Geiger in Germany. These experiments showed that individual scattered $X$-ray photons and recoil electrons appear at the same instant in time, contrary to some views that were then being developed by Bohr, Kramers and Slater in an attempt to reconcile quantum views with the continuous waves of electromagnetic theory.

Compton also discovered the phenomenon of total reflexion of X-rays, and their complete polarization (with C. F. Hagenow), and first obtained (with R. L. Doan) X-ray spectra from ruled gratings. This latter work had an important consequence in leading to a distinct improvement in our knowledge of the electronic charge. By measuring an $\mathrm{X}$-ray wave-length with a ruled grating of known grating space, and then using a crystal to diffract the same rays, one can determine the absolute value of the grating space of the crystal. Combining this with the measured crystal density, it is possible to obtain the Avogadro number, and combining this with the Faraday, the electronic charge is obtained. The outcome was that the Millikan oil drop value had to be revised from 4.774 to $4.803 \times 10^{-10}$ c.g.s. E.S.U., it being finally recognized that systematic errors had been made in measuring the viscosity of air, a quan. tity which enters into the oil drop method.

From about 1930 , Compton directed his attention mainly to the study of cosmic rays. In the next ten years he was in charge of a major programme involving a world-wide study of the geographic variations of their intensity. This resulted in full confirmation of some observations made in 1927 by J. Clay, indicating a latitude effect on the intensity. The world survey, in the service of which Compton made many long voyages, showed correlation of the intensity of cosmic rays with geomagnetic, rather than geographic latitude. This opened the way for extensive subsequent studies of the interaction of the Earth's magnetic field with the incoming isotropic stream of primary charged particles.

In 1941 he was appointed chairman of the National Academy of Sciences Committee to Evaluate Use of Atomic Energy in War. In the autumn of 1941 this Committee worked with those responsible for studying this same problem in Great Britain, and also with the $S-1$ committee headed by Dr. L. J. Briggs, then director of the National Bureau of Standards. This led to recommendations to the United States Government for the setting up of a major effort starting in January 1942. Compton assumed the active direction of the group, which was known by the 'cover-name' of Metallurgical Laboratory of the University of Chicago, which concentrated on development of controlled uranium fission reactors for the production of plutonium. Within the year the first controlled uranium fission reactor was operating at Chicago, this specifie project being largely due to the efforts of E. Fermi, L. Szilard, E. P. Wigner, and a host of co.workers. More experimental reactors were designed and built at Oak Ridge, Tennessee, and at the newly established Argonne Laboratory in the suburbs of Chicago. Here was carried out the work which led to the large plutonium-producing reactors built at
Hanford, Washington, which produced the plutonium for the atom bomb that destroyed Nagasaki in August 1945.

Throughout the War, Compton also played an important part in the general planning of the atom bomb project, including the setting up of the laboratory at Los Alamos, New Mexico, and in reaching the military-political decisions about the use of the bombs in Japan. $\mathrm{He}$ has given a personal account of these matters in his book, Atomic Quest (Oxford University Press, 1956).

Compton became chancellor of Washington University in 1945, bringing with him a close associate from the days of his work on cosmic rays, Joyce Stearns, as dean of faculties. He turned with great vigour to the task of re-making a University which had greatly suffered through the depression years and the War years. In eight years filled with hard work he set it along a path toward greatness along which it continues to move. Then in $\mathbf{1 9 5 3}$ he asked to be relieved from administrative duties, so that he could return to teaching, and devote himself entirely to problems of the social impact of science and technology, and to ways of promoting world brotherhood and the relieving of international tensions. He was planning to continue active work on such problems into the retirement which ended soon after it began.

He is survived by his wife, formerly Betty Charity McCloskey, and two sons, Arthur Allen, now in the American Foreign Service stationed at Manila in the Philippines, and John Joseph, a professor of philosophy at Vanderbilt University (Nashville, Tennessee), and by a brother, Wilson Compton, now retired, a former president of Washington State University (Pullman, Washington). Another brother, Karl Taylor Compton, former president of the Massachusetts Institute of Technology, died in 1954.

\section{E. U. CoNDON}

\section{Prof. A. E. Douglass}

Dr. Andrew EllicotT Douglass, the noted American astronomer and founder of tree-ringdating research, died on March 20, aged ninety-four.

Dr. Douglass was born in Windsor, Vermont, on July 5,1867 . At the time of his death, he held four titles in the University of Arizona, where he had been a member of the faculty since 1906: professor of astronomy, professor of dendrochronology, and director emeritus of both the University's Steward Observatory and Laboratory of Tree-Ring Research. His professorships had been on a part-time basis in recent years.

Dr. Richard A. Harvill, president of the University of Arizona, writes: "Dr. Douglass was a brilliant scientist who served the University of Arizona with great distinction for fifty-five years. He was highly creative and extremely versatile in the range of his interests and contributions. Throughout the world, when the University of Arizona was mentioned scientific leaders immediately thought of Dr. Douglass. But he was more than a great scholar. He was a man of most admirable personal qualities. He exemplified qualities of simplicity and of humanity that are traits of a truly great man".

Dr. Douglass went to Arizona in 1894 to assist in selecting a site for the Lowell Observatory. After inspecting many locations, he recommended Flagstaff, and the Observatory that later became famous for planetary research was established there on his 